\title{
Sensitivity analysis of ground settlement induced by pipe-jacking construction in soft soil stratum
}

\author{
Xianmin $\operatorname{Han}^{1}$, Wenjiang $\mathrm{Li}^{1 *}$, Tao Chen ${ }^{2}$ and Wang Liu ${ }^{1}$ \\ ${ }^{1}$ School of civil engineering, Shijiazhuang Tiedao University, Shijiazhuang, Hebei, 050043, China \\ ${ }^{2}$ Shijiazhuang Electrical Design Research Institute Co., Shijiazhuang, Hebei, 050000, China
}

\begin{abstract}
Taking the ground settlement while pipe-jacking construction in soft soil as the engineering background, the effect of pipe jacking were studied by numerical simulation. It focused on the factors that mainly influenced surface settlement of ground including in-situ stress release rate (or ground loss ratio), chamber pressure, elastic modulus of soil, buried depth and diameter of pipe. That would provide theoretical basis for taking measures to reduce surface subsidence while jacking. The main conclusions were as follows: (1) The in-situ stress release rate and pipe diameter were proportional to the surface subsidence. (2) Chamber pressure, elastic modulus and buried depth were inverse proportional to the surface subsidence. (3) From the point of view of the influence on surface settlement, the sensitivity of pipe diameter and elastic modulus of soil was the greatest, followed by burial depth and chamber pressure, and the stress release rate was the smallest.
\end{abstract}

\section{Introduction}

In pipe-jacking construction, there are three commonly used equilibrium theories: air pressure balance, sludge balance and earth pressure balance. Each of those has its own characteristics. At present, the earth pressure balanced pipe jacking machine is widely used in municipal construction. The main reason is that it has a wide range of applications, relatively simple equipment and the sludgemud is easy to handle [1].

As a construction concept and construction theory, earth pressure balanced pipe-jacking construction has two basic contents. One is that water and earth pressure applied to working face should be kept in balanced state during jacking. Another is that amount of excavation and output of soil should also be in equilibrium state.

One of the major advantages of pipe-jacking construction is that it could control settlement of ground surface well. Relevant scholars have done some research on disturbance mechanism on surrounding soil, influencing factors and control technology on ground settlement during jacking. Fang Yingguang et al. [2,3] studied the disturbance mechanism of pipe-jacking construction by field monitoring and test. Feng Haining et al. $[4,5]$ studied the variation law of soil pressure, pore water pressure, underground water level and stratum settlement under pipe jacking construction through model test and numerical calculation. The influence of earth pressure, friction and nose deflection of machine on surface settlement was studied by numerical method [6]. Huang Hongwei [7] simulated the mechanical effect of pipe-jacking construction by numerical analysis method, considering chamber pressure, stratum loss, grouting and joint action.

The research results show that there are many factors affecting the ground settlement in pipe-jacking construction. And the systematic research conclusion have not yet been achieved. Soft clay has high compressibility, high water content, high sensitivity, low strength and permeability. So it is more difficult to control the settlement during jacking in soft clay stratum. If poorly controlled during jacking, it will cause larger stratum settlement. And that will have a harmful impact on nearby buildings. Therefore, the main factors affecting surface settlement, such as ground loss ratio, chamber pressure, buried depth of pipe-jacking, elastic modulus of soil and pipe diameter, are selected to carry out the sensitivity analysis on ground settlement during pipe-jacking construction in soft clay layer. That would provide a basis for taking measures to reduce surface settlement.

\section{Basic assumption for pipe-jacking simulation}

Three-dimensional numerical simulation of jacking process is based on the following assumptions:

- Soil is assumed to behave as isotropic elastic-plastic medium.

- $\quad$ Pipe-jacking is $3.0 \mathrm{~m}$ in internal diameter, $0.3 \mathrm{~m}$ in wall thickness. The pipe is isotropic linear elastomer without considering the influence of 
joint.And the material is C50 reinforced concrete.

- Chamber pressure is trapezoidal load perpendicular to the tunnel face, and the static earth pressure is used as the benchmark.

- The grouting pressure is directed radially to the soil around the outer hole of pipe-jacking, which is 1.1 times of the static earth pressure. The grouting pressure corresponds to the actual construction, and the grouting length is $18 \mathrm{~m}$ behind the working face.

- Pipeline is in close contact with slurry sleeve, and pipe-soil does not slip or detach during jacking. The effect of pipe-jacking on slurry sleeve is simulated by applying tangential force.

- In-situ stress release method is used to simulate the formation loss. To implement this, girdpoint reaction force is applied to the surrounding soil of pipe-jacking.

- The influence of groundwater is reflected by soil physical and mechanical parameters.
- In the process of pipe jacking, rheological properties of soil is not considered, but the distance change during pipe-jacking is considered.

\section{Numerical calculation model and simulated working condition}

\subsection{Numerical calculation model}

Three-dimensional finite difference software is used for numerical calculation. The numerical model has a width of $80 \mathrm{~m}$, a length of $96 \mathrm{~m}$ and a height of $24 \mathrm{~m}$. Soil is simulated by solid element, following Mohr-Coulomb yield criterion. Pipe-jacking is simulated by shell element and treated by elastic medium. Slurry sleeve is simulated by solid element. The physical and mechanical parameters used in the calculation are shown in Table 1.

Table 1. Physical and mechanical parameters of materials

\begin{tabular}{ccccccc}
\hline $\begin{array}{c}\text { Material } \\
\text { parameters }\end{array}$ & $\begin{array}{c}\text { Density } \\
\rho /\left(\mathrm{kN} \cdot \mathrm{m}^{-3}\right)\end{array}$ & $\begin{array}{c}\text { Thickness } \\
/ \mathrm{m}\end{array}$ & $\begin{array}{c}\text { Modulus of } \\
\text { elasticity } / \mathrm{MPa}\end{array}$ & $\begin{array}{c}\text { Poisson } \\
\text { ratio } / \nu\end{array}$ & $\begin{array}{c}\text { Cohesion } \\
/ \mathrm{kPa}\end{array}$ & $\begin{array}{c}\text { Internal friction } \\
\text { angle } /{ }^{\circ}\end{array}$ \\
\hline Soil & 17 & - & 8.0 & 0.32 & 16 & 18 \\
Pipe-jacking & 25 & 0.3 & $34.5 \mathrm{e} 3$ & 0.2 & - & - \\
Slurry sleeve & 11.2 & 0.02 & 4.0 & 0.49 & - & - \\
\hline
\end{tabular}

soil parameters and pipe-jacking construction parameters,

\subsection{Simulated working conditions} a total of 26 working conditions were designed for research, as listed in Table 2.

According to the relevant survey data of pipe-jacking,

Table 2. Calculation conditions

\begin{tabular}{|c|c|c|c|c|c|c|c|c|c|}
\hline $\begin{array}{c}\text { Working } \\
\text { condition } \\
\text { number }\end{array}$ & $\begin{array}{c}\text { Stress } \\
\text { release } \\
\text { rate } / \% \\
\end{array}$ & $\begin{array}{c}\text { Chamber } \\
\text { pressure/ } \\
\mathrm{kPa} \\
\end{array}$ & $\begin{array}{c}\text { Elastic } \\
\text { modulus of } \\
\text { soil/MPa } \\
\end{array}$ & $\begin{array}{c}\text { Pipe } \\
\text { diameter } \\
/ \mathrm{m}\end{array}$ & $\begin{array}{l}\text { Working } \\
\text { condition } \\
\text { number }\end{array}$ & $\begin{array}{c}\text { Stress } \\
\text { release } \\
\text { rate } / \% \\
\end{array}$ & $\begin{array}{c}\text { Chamber } \\
\text { pressure/ } \\
\mathrm{kPa} \\
\end{array}$ & $\begin{array}{c}\text { Elastic } \\
\text { modulus of } \\
\text { soil/MPa }\end{array}$ & $\begin{array}{c}\text { Pipe } \\
\text { diameter } \\
/ \mathrm{m}\end{array}$ \\
\hline 1 & 5 & \multirow{6}{*}{100} & \multirow{6}{*}{8.0} & \multirow{6}{*}{3.0} & 14 & \multirow{4}{*}{5} & \multirow{4}{*}{225} & 4.0 & \multirow{4}{*}{3.0} \\
\hline 2 & 10 & & & & 15 & & & 8.0 & \\
\hline 3 & 15 & & & & 16 & & & 10.0 & \\
\hline 4 & 20 & & & & 17 & & & 12.0 & \\
\hline 5 & 25 & & & & 18 & \multirow{4}{*}{5} & 60 & \multirow{4}{*}{8.0} & \multirow{4}{*}{3.0} \\
\hline 6 & 30 & & & & 19 & & 100 & & \\
\hline 7 & \multirow{7}{*}{5} & 60 & \multirow{7}{*}{8.0} & \multirow{7}{*}{3.0} & 20 & & 175 & & \\
\hline 8 & & 80 & & & 21 & & 225 & & \\
\hline 9 & & 100 & & & 22 & \multirow{5}{*}{30} & \multirow{5}{*}{100} & \multirow{5}{*}{8.0} & 1.0 \\
\hline 10 & & 125 & & & 23 & & & & 1.5 \\
\hline 11 & & 175 & & & 24 & & & & 2.0 \\
\hline 12 & & 225 & & & 25 & & & & 2.5 \\
\hline 13 & & 275 & & & 26 & & & & 3.0 \\
\hline
\end{tabular}

Note: Chamber pressure refers to the value at the center of working face.

\section{Effect of stress release rate on surface settlement}

The numerical calculation simulated six working contions of in-situ stress release rate. They are 5\%,10\%, $15 \%, 20 \%, 25 \%$ and $30 \%$, which separately corresponds to the grouting saturation of $95 \%, 90 \%, 85 \%, 80 \%, 75 \%$ and $70 \%$. Buried depth of pipe-jacking is $7.2 \mathrm{~m}$.
In order to study the influence of different stress release rates on the settlement and deformation of strata, four typical measuring lines are set up. Their locations are surface, $1.8 \mathrm{~m}$ below surface (i.e. $1 / 2$ diameter), $3.6 \mathrm{~m}$ below surface (i.e.pipe diameter) and $-5.1 \mathrm{~m}$ below surface (i.e. top of pip ). The lateral settlement curves of strata under typical stress release rates are shown in Figure 1. The variation relationship between maximum settlement values of soil and stress release rates are 
shown in Figure 2. The surface settlement curves along longitudinal direction are shown in Figure 3.

The calculation results show that: (1) With the increase of in-situ stress release rate, the maximum settlement value of stratum increases by a linear proportional relationship. While the stress release rate increases from $5 \%$ to $30 \%$ (6 times), the average settlement of stratum increases by about 1.14 times. (2) To overlying stratum on pipe jacking, the closer of distance between pipe-jacking and layer, the bigger of

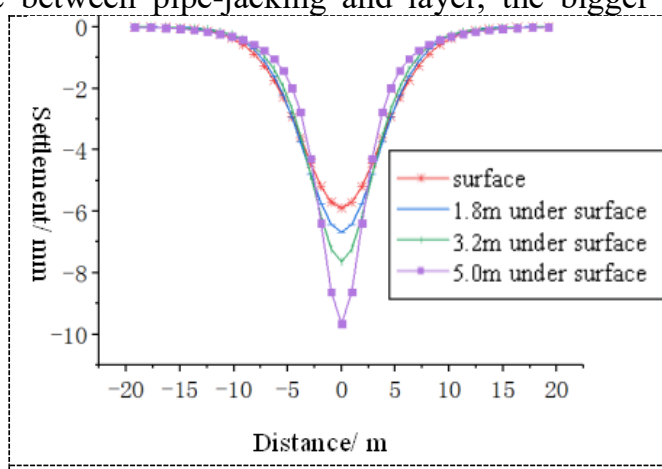

Figure 1. Transverse settlement curve of stratum under $10 \%$ stress release rate

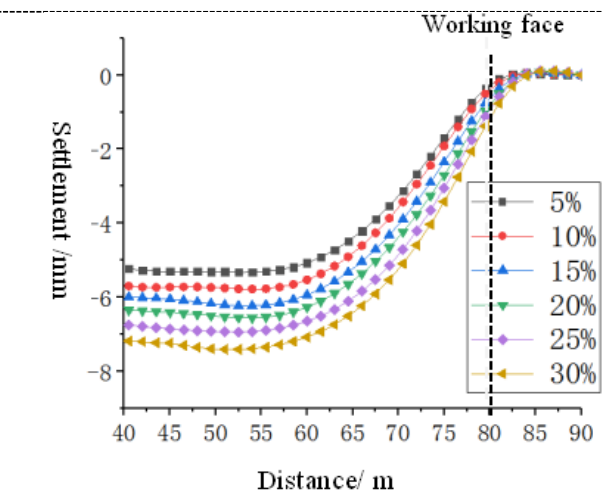

Figure 3. Longitudinal settlement curve of surface under different stress release rate the settlement, and the larger of the disturbance. (3) The law of subsidence attenuation is that the farther away from pipe jacking, the slower subsidence attenuation. (4) From the longitudinal settlement curve of the surface, it can be seen that the disturbance influence scope of pipe jacking construction is mainly 7 times of pipe-jacking diameter behind the working face because of multiple grouting. But the real influencing range of jacking is 2 times except for the influence range of multiple synchronous grouting.

\section{.}

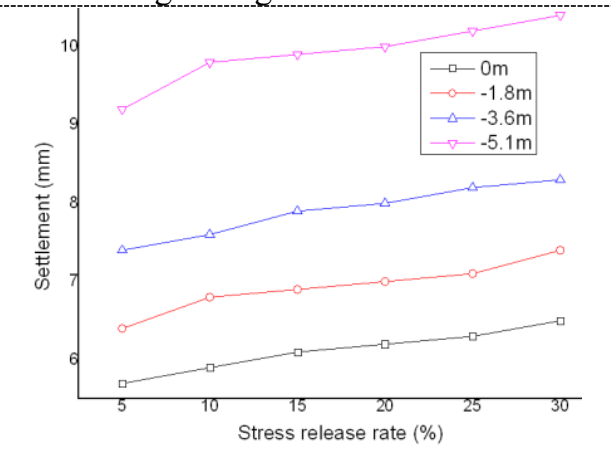

Figure 2. Maximum settlement vaule of stratum under different stress release rate

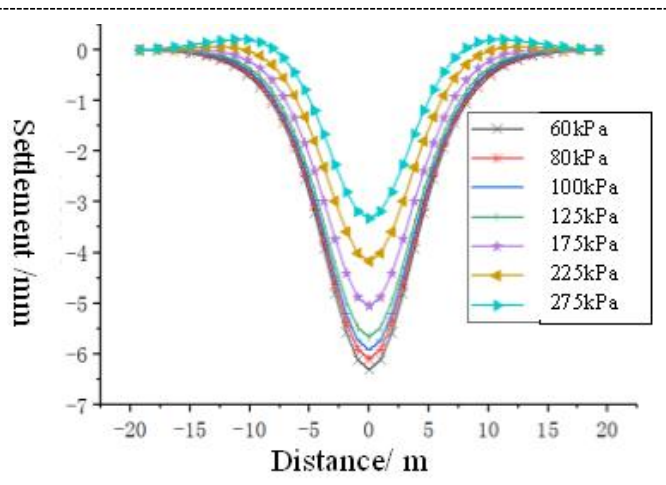

Figure 4. Transverse settlement curves of surface under different chamber pressure

$175 \mathrm{kPa}, 225 \mathrm{kPa}$ and $275 \mathrm{kPa}$, respectively. The buried depth of pipe-jacking was $11 \mathrm{~m}$.

Surface settlement curve along transverse and longitudinal direction are shown in Figure 4 and Figure 5. Maximum settlement of surface under different chamber pressures is shown in Figure 6.

In order to analyze the influence of the chamber pressure on the surface settlement, seven working conditions were simulated, that are $60 \mathrm{kPa}, 80 \mathrm{kPa}, 100 \mathrm{kPa}, 125 \mathrm{kPa}$,

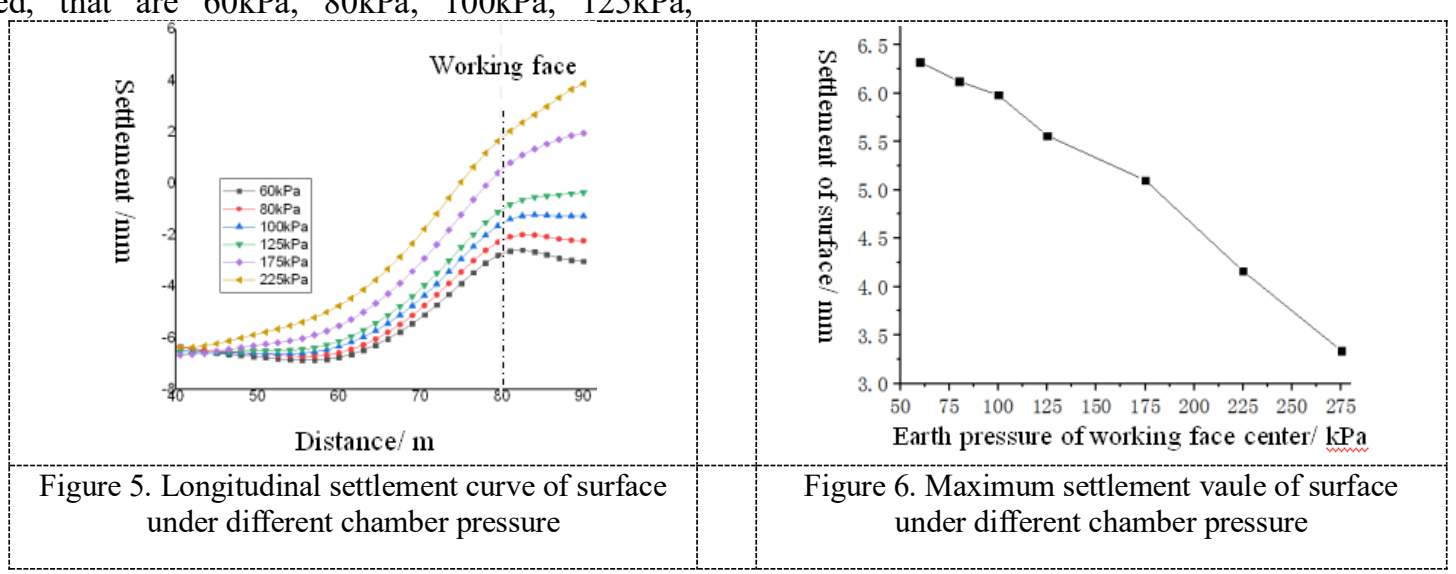

The results show that: (1) With the increase of the surface decreases gradually from $6.32 \mathrm{~mm}(60 \mathrm{kPa})$ to chamber pressure, the ultimate settlement value of the 
pressure increases by 4.58 times, the surface settlement decreases by $47.2 \%$. (2) The width of the transverse settlement trough of the surface presents a decreasing trend while the chamber pressure increase. (3) From the surface settlement curve alone longitudinal direction, it can be seen that the greater the pressure of the chamber, the larger the longitudinal influence range of the surface settlement. When the chamber pressure is greater than $125 \mathrm{kPa}$, there is obvious uplift phenomenon appeared ahead of the tunnel face.

\section{The effect of elastic modulus of soil on surface settlement}

In order to analyze the influence of elastic modulus of soil on surface settlement of pipe-jacking construction, four elastic moduli are selected. That are 4.0 $\mathrm{MPa}, 8.0$ $\mathrm{MPa}, 10.0 \mathrm{MPa}$ and $12.0 \mathrm{MPa}$. The variation of transverse settlement and longitudinal settlement curve of surface under different elastic modulus of soil are shown in Figure 7 and Figure8. And the maximum settlement of surface under different elastic modulus of soil is shown in Figure 9.

The results show that: (1) With the increase of elastic modulus of soil, the maximum settlement value of the surface decreases gradually. The reason is tha the greater the elastic modulus of soil, the smaller the compressibility. This would cause smaller unloading rebound deformation while jacking; (2) The maximum settlement value of the surface decreases from $7.6 \mathrm{~mm}$ to $3 \mathrm{~mm}$ when the elastic modulus increase from $4.0 \mathrm{MPa}$ to $12 \mathrm{MPa}$. This manifest that when the elastic modulus increases 3 times, and the maximum settlement decreases by $60.5 \%$. (3) While the chamber pressure is constant, the smaller the elastic modulus of the soil, the more prominent the surface bulge ahead of the tunnel face.

\begin{tabular}{|c|c|}
\hline $\begin{array}{c}\text { Distance/ } \mathrm{m} \\
0\end{array}$ & 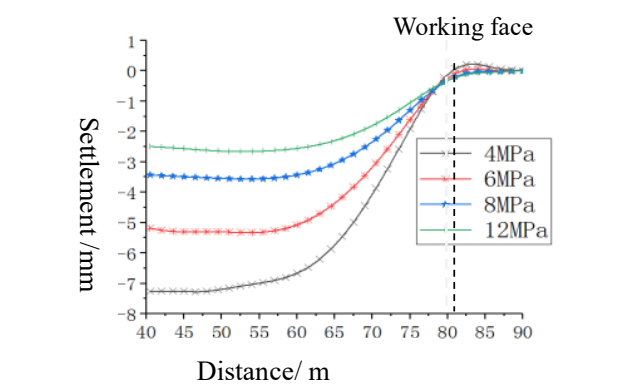 \\
\hline $\begin{array}{l}\text { Figure 7. Transverse settlement curves of surface } \\
\text { under different elastic modulus of soil }\end{array}$ & $\begin{array}{l}\text { Figure 8. Longitudinal settlement curve of surface } \\
\text { under different elastic modulus of soil }\end{array}$ \\
\hline 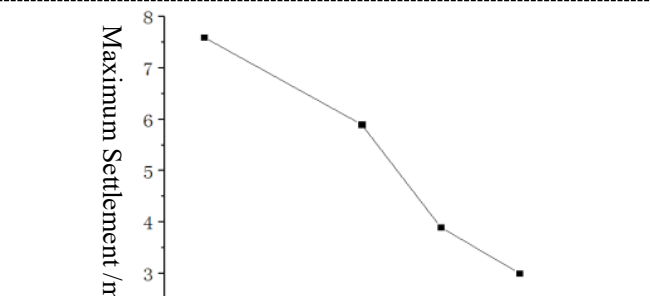 & 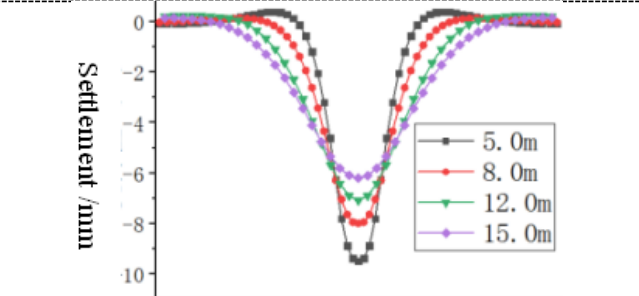 \\
\hline 12 & $\begin{array}{lllllllll}-20 & -15 & -10 & -5 & 0 & 5 & 10 & 15 & 20\end{array}$ \\
\hline Elastic modulus of soil/ MPa & Distance/m \\
\hline $\begin{array}{l}\text { Figure 9. Relation between different elastic } \\
\text { modulus and maximum surface settlement }\end{array}$ & $\begin{array}{l}\text { Figure 10. Transverse settlement curves of surface } \\
\text { under different buried depth of pipe }\end{array}$ \\
\hline
\end{tabular}

\section{Effect of buried depth of pipe-jacking on surface settlement}

In pipe-jacking construction, it is generally required that the buried depth of pipe is more than 1 times the diameter of the tunnel. And pipe-jacking construction in shallow buried depth is liable to cause surface uplift. But if the burial depth is too deep, the resistance increases when jacking. So the buried depth of pipe-jackig is generally less than 15 meters. Therefore, the calculation conditions of pipe-jacking buried depth considered are $5 \mathrm{~m}, 8 \mathrm{~m}, 12 \mathrm{~m}$ and $15 \mathrm{~m}$.

The subsidence curves of transverse and longitudinal direction under different burial depths are shown in Figure 10 and Figure 11. And the maximum subsidence under different burial depths is shown in Figure 12.
The calculation results show that: (1) With the increase of burial depth, the influence of pipe jacking construction on surface settlement become smaller, which basically shows a linear inverse relationship. (2) When burial depth of pipe-jacking increase from $5 \mathrm{~m}$ to $15 \mathrm{~m}$, the maximum settlement reduces from $9.5 \mathrm{~mm}$ to $6.2 \mathrm{~mm}$. That is that while the burial depth increases by 3.0 times, the settlement decreases by $34.7 \%$. (3) When the burial depth of pipe jacking is smaller, the lateral surface settlement decreases by $34.7 \%$; (4) When the burial depth of pipe jacking is small, the settlement trough become narrow and deep. And when the buried depth is large, the settlement trough become wide and shallow. (5) The larger the buried depth of pipe, the smaller the influence scope of pipe-jacking construction on the surface. 


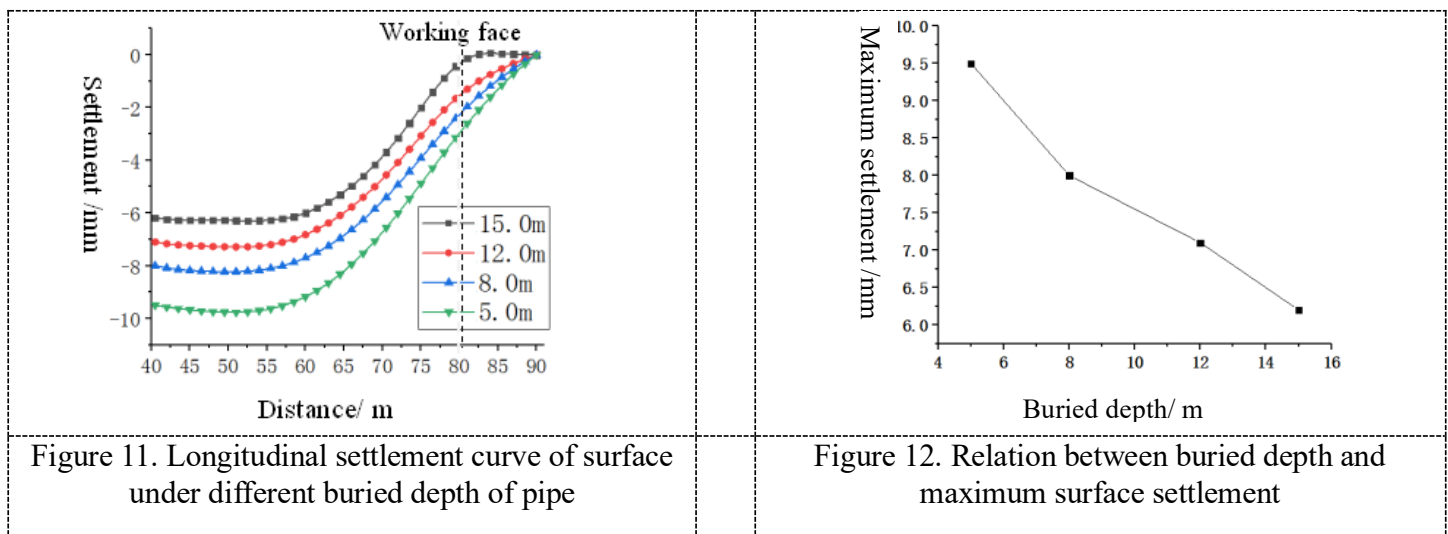

\section{Effect of pipe diameter on surface settlement}

In order to study the influence of pipe-jacking dimension on surface settlement in jacking construction, five different inner diameter pipes were selected for analysis. The inner diameter value are $1.0 \mathrm{~m}, 1.5 \mathrm{~m}, 2.0 \mathrm{~m}, 2.5 \mathrm{~m}$ and $3.0 \mathrm{~m}$ respectively. The wall thickness was selected according to the code [8].
The transversal and longitudinal subsidence curves of the surface under different pipe diameters are shown in Figure 13 and Figure 14 respectively.

The results show that: (1) When the burial depth is constant, the larger the pipe diameter is, the larger the surface subsidence. (2) When the pipe diameter increases by 3 times, the surface subsidence almost increases by 6 times. And the surface subsidence is linearly proportional to pipe diameter. (3) The larger the pipe diameter, the larger the scope of the transversal and longitudinal subsidence.

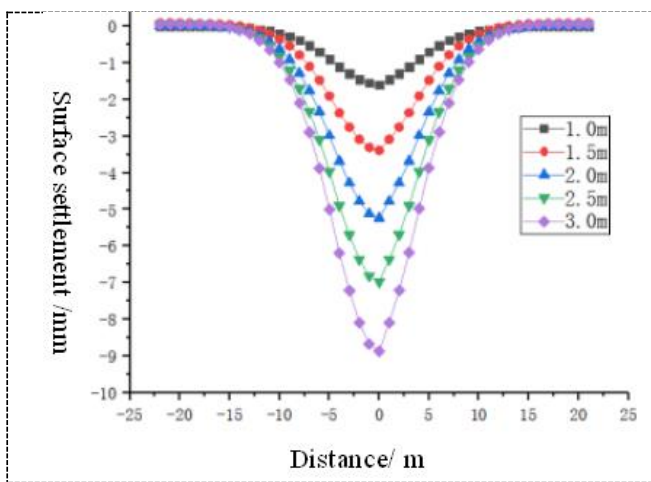

Figure 13. Transverse settlement curves of surface under different pipe diameter

\section{Conclusions}

By means of numerical simulation, the influence of in-situ stress release rate, chamber pressure, buried depth of pipe-jacking, elastic modulus of soil and pipe diameter on ground settlement are analyzed during pipe-jacking construction in soft clay stratum. The following conclusions can be drawn:

(1) There is a non-linear positive proportional relationship between in-situ stress release rate and stratum subsidence. When the stress release rate increases by 6 times, the stratum subsidence almost increases by 1.14 times.

(2) There is a non-linear inverse proportional relationship between the earth silo pressure and the ground settlement. And the width of the transverse settlement trough decreases with the increase of the earth silo pressure.

(3) The modulus of elasticity of soil is inversely proportional to the surface settlement. When the modulus of elasticity increases by 3 times, the maximum surface settlement decreases by about $2 / 3$. The smaller the

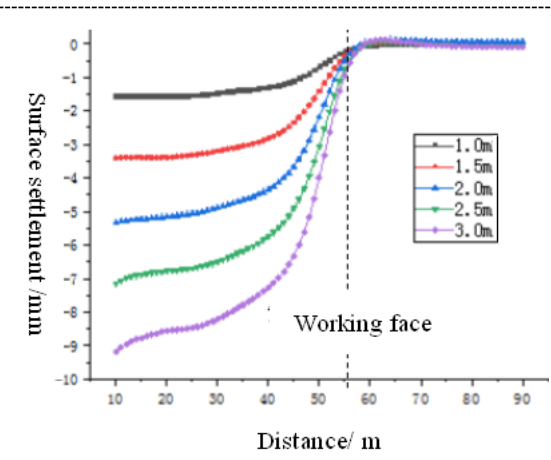

Figure 14. Longitudinal settlement curve of surface under different pipe diameter

modulus of elasticity of soil, the more obvious the surface bulge ahead of the tunnel face.

(4) When the buried depth of pipe-jacking increases, the surface settlement decreases. when the buried depth of pipe-jacking is small, the surface transverse settlement trough become narrow and deep. And when the buried depth of pipe-jacking is large, the settlement trough become wide and shallow.

(5) When the buried depth of pipe-jacking is fixed, the larger the diameter of the pipe is, the bigger the ground settlement is. And the range of surface transverse and longitudinal subsidence become larger while diameter of the pipe increase.

(6) It is more difficult to control the ground settlement of soft clay stratum and more sensitive to construction parameters of pipe-jacking. It can be drawn from the comprehensive analysis that the sensitivity of pipe diameter and elastic modulus of soil is the greatest, followed by burial depth and silo pressure, and the stress release rate is the smallest. 


\section{Acknowledgments}

This article was funded by State Grid Science and Technology Project (NO:5204BB18001G), China Railway Siyuan Survey and Design Group Science and Technology Project.

\section{References}

1. Yu B.Q., Chen, C.C. (1998) Construction technology of pipe jacking. China Communications Press, Beijing.

2. Fang, Y.G, Mo H.H., Zhang C.Y. (2003) Theoretic and testing analysis of soil deformation in th area of disturbance caused by pipe-jacking. Chinese Journal of Rock Mechanics and Engineering, 22(4): 601-605.

3. Wei G., Xu R.Q., Tu W. (2004) Test study and analysis on soil disturbance induced by pipe jacking construction. Chinese Journal of Rock Mechanics and Engineering, 23(3): 476-482.

4. Feng H.N., Wen X.G., Wei G., et al. (2003) In-situ test reserach on influence of pipe jacking on soil. Rock and Soil Mechanics, 24(5):781-785.

5. Wei G., Wu H.J., Chen C.L. (2007) Prediction of settlement induced by ground loss during pipe jacking construction. Rock and Soil Mechanics, 28(2): 359-363.

6. Feng H.N., Gong X.N., Xu R.Q. (2004) Finite analysis of influnce of pipe-jacking construction on environments. Chinese Journal of Rcck Mechanics and Engineering, 23(7): 1158-1162.

7. LI N. (2003) 3D numerical analysis on condtruction mechanics effect of pipe-jacking. Chinese Journal of Rcck Mechanics and Engineering, 22(3): 400-406.

8. Ministry of Industry and Information Technology of the People's Republic of China. (2010) Reiforced concrete sewer pipes used for jacking construction: JC/T640-2010. 